\title{
Numerical modelling of a hemp concrete wall
}

\author{
Georges Costantine ${ }^{1, *}$, Chadi Maalouf ${ }^{1}$, Tala Moussa $^{1}$, Guillaume Polidori ${ }^{1}$, and Elias Kinab ${ }^{2}$ \\ ${ }^{1}$ GRESPI, SFR Condorcet FR CNRS 3417, University of Reims Champagne Ardenne, 51687 Reims, Cedex 2, France \\ ${ }^{2}$ Faculty of Engineering - Lebanese University, Roumieh Campus - Lebanon
}

\begin{abstract}
In a global warming context associated to the abuse of energy consumption, actual researches focus more and more on reducing energy costs in the building sector. This target could be achieved by using innovative building materials, such as hemp concrete, due to its positive impacts on thermal and environmental levels. The aim of this work is to carry out a numerical study of a hemp concrete wall subjected to several indoor and outdoor conditions of temperature and relative humidity using the program object oriented SPARK. The hygrothermal behaviour of the wall is investigated taking into account heat and moisture transfer within the wall as well as hysteresis phenomenon between the sorption and desorption curves and their temperature dependency.
\end{abstract}

\section{Introduction}

Actually, as mentioned in the French Thermal Regulations of 2012 [1] and in the United Nations Environmental Program of 2016 UNEP [2], buildings are the most energy consuming sector. In France, they are responsible of almost $43 \%$ of the total energy consumption. In a context of promoting energy efficiency, building sector has undergone a notable evolution towards innovative construction insulation materials [3] [4] such as the hemp concrete.

Hemp concrete is obtained by mixing hemp shives to a mineral binder (lime), water and some additives. Plentiful works are carried out on hemp concrete at the material and wall scales and its experimental characterization is widely available [5][6][7]. Recent works have shown also the importance of including hysteresis effect [8] [9][10] and temperature dependency $[9][11][12]$ in modelling its hygrothermal behaviour to assess relative humidity profiles within the walls.

In this context, the aim of this work is to investigate numerically the hygrothermal behaviour of a hemp concrete wall subjected to real weather conditions [8] and to assess the impact of different modelling approaches on the prediction of temperature and humidity conditions within the wall. For this purpose, four models are compared: a standard model for heat and moisture transfer, a model with hysteresis effect, a model with sorption temperature dependency and finally a global model taking into account both aspects. The oriented object simulation tool SPARK [13] is used to solve the different models using the finite difference method.

\section{Numerical study}

\subsection{Review on moisture transfer in a single building material}

Coupled heat and moisture transfer models for a simple layer building materials are studied in several researches: Künzel [14] developed a model in which moisture transfer is due to relative humidity and temperature gradients. In 1997, Mendes and al. [15] showed a model based on the theory of Philip and De Vries [16], with similar assumptions as Künzel, but this time moisture transfer is governed by volumetric moisture content gradient. Thus, Umidus model [15] is created : both diffusion and capillary regimes are taken into account and the transfer of water in the vapor and liquid phases through the material can be analysed for any climate. Moreover, in 1989, Kerestecioglu and $\mathrm{Gu}$ [17] investigated the phenomenon using the evaporation-condensation theory in unsaturated liquid flow stage. In addition, Burch and Thomas [18] developed a computational model using finite-difference method able to estimate heat and mass transfers through composite walls under non-isothermal conditions. Morover, the model of Ozaki and al. [19] takes into account the moisture transfers in both liquid and vapor phases coupled to the heat generated by the phase change due to the moisture sorption process.

\subsection{Mathematical model}

In this study, Umidus model, where moisture is transported under liquid and vapor phases, is used. The mass conservation equation is given by:

\footnotetext{
* Corresponding author: georges.costantine@ univ-reims.fr
} 


$$
\frac{\partial \theta}{\partial t}=\frac{\partial}{\partial x}\left(D_{T} \frac{\partial T}{\partial x}\right)+\frac{\partial}{\partial x}\left(D_{\theta} \frac{\partial \theta}{\partial x}\right)
$$

With the following boundary conditions $(\mathrm{x}=0$ and $\mathrm{x}$ $=\mathrm{L})$ :

$$
\begin{gathered}
-\left.\rho_{l}\left(D_{T} \frac{\partial T}{\partial x}+D_{\theta} \frac{\partial \theta}{\partial x}\right)\right|_{x=0, e} \\
=h_{M, e}\left(\rho_{v, a, e}-\rho_{v, s, e}\right) \\
-\left.\rho_{l}\left(D_{T} \frac{\partial T}{\partial x}+D_{\theta} \frac{\partial \theta}{\partial x}\right)\right|_{x=L, i} \\
=h_{M, i}\left(\rho_{v, s, i}-\rho_{v, a, i}\right)
\end{gathered}
$$

"e" and "i" represent respectively the outside and inside, "s" refers to the wall surface, and "a" to the ambient air. $D_{T}=D_{T l}+D_{T v}$ and $D_{\theta}=D_{\theta l}+D_{\theta v}$, where $D_{T l}$ is the liquid phase transport coefficient associated to a temperature gradient, $D_{T v}$, the vapor phase transport coefficient associated to a temperature gradient, $D_{\theta l}$, the liquid phase transport coefficient associated to a moisture content gradient, $D_{\theta v}$, the vapor phase transport coefficient associated to a moisture content gradient, $D_{T}$, the mass transport coefficient associated to a temperature gradient and $D_{\theta}$, the mass transport coefficient associated to a moisture gradient [20].

$$
D_{\theta}=\frac{\delta_{a}}{\mu} \frac{P_{v s}}{\rho_{0}} \frac{1}{\xi}
$$

Vapor transport coefficient under a temperature gradient is given by the relation:

$$
D_{T, v}=\phi \frac{\delta_{a}}{\rho_{l} \mu} \frac{d P_{v s}}{d T}
$$

$D_{\theta v}$ is expressed as follows:

$$
D_{\theta v}=\frac{D_{T v} \times P_{s a t}}{\xi\left(\emptyset \times \frac{d P_{v s}}{d T}+P_{s a t} \times \frac{1}{\xi} \times \xi_{T}\right)}
$$

One dimensional model of the energy conservation equation with coupled temperature and moisture for a porous media is considered, and the effect of the absorption or desorption heat is added. This equation is written as:

$$
\begin{aligned}
\rho_{0} C p_{m} \frac{\partial T}{\partial t}=\frac{\partial}{\partial x} & \left(\lambda(T, \theta) \frac{\partial T}{\partial x}\right) \\
& +L_{v} \rho_{l}\left(\frac{\partial}{\partial x}\left(D_{T, v} \frac{\partial T}{\partial x}\right)\right. \\
& \left.+\frac{\partial}{\partial x}\left(D_{\theta, v} \frac{\partial \theta}{\partial x}\right)\right) \\
C p_{m}= & C p_{0+} C p_{l} \frac{\rho_{l}}{\rho_{\theta}}
\end{aligned}
$$

where $\mathrm{C}_{\mathrm{pm}}$ is the average specific capacity, which takes into account the dry material specific heat and the contribution of the specific heat of the liquid phase. $\lambda$ is the thermal conductivity depending on moisture content and the temperature in Kelvin.

Boundary conditions take into account radiation, heat and phase change.

$$
\begin{aligned}
\left(-\lambda \frac{\partial T}{\partial x}\right)_{x=0, e}- & L_{v} \rho_{l}\left(D_{T, v} \frac{\partial T}{\partial x}\right. \\
& \left.+D_{\theta, v} \frac{\partial T}{\partial x}\right)_{x=0, e} \\
& =h_{T, e}\left(T_{a, e}-T_{s, e}\right) \\
& +L_{v} h_{M, e}\left(\rho_{v e, a, e}\right. \\
& \left.-\rho_{v e, s, e}\right)+\emptyset_{\text {ray }, e}
\end{aligned}
$$

\subsection{Hysteresis modelling}

Hysteresis is observed between the sorption curves of hygroscopic building materials. Physically, sorption curves describe the equilibrium between the water content of the material and the relative humidity of the surrounding air. The hysteresis phenomenon is due to the "ink bottle" effect [21] which can be explained by the fact that water isn't retained in the materials' pores at the same manner it fulfils them. Litterature provides many models describing the hysteresis phenomenon in porous materials: in fact, three global models can be distinguished: physical models developed by Mualem [22], mathematical models of Cool and Parker [23], and empirical models proposed by Pedersen [24]. New researches done by Steeman [25] and Van Belleghem [26] showed that hysteresis influences the moisture transfer in 1 porous materials. Moreover and particularly in hemp concrete, Samri [27], and Lelievre et al. [28] have proved the importance of considering the hysteresis phenomenon in global transfer models (heat, air and moisture).

In this article, the empirical model proposed by Pedersen [24] to describe the hysteresis that occurs in hygroscopic materials like wood is used and adapted for the hemp concrete case. Main adsorption and desorption curves are given in equations (14) and (15):

$$
\begin{aligned}
& \frac{U(\varphi)}{U_{\max }}=\left(1-\frac{\ln (\varphi)}{A_{a}}\right)^{\frac{-1}{n_{a}}} \\
& \frac{U(\varphi)}{U_{\max }}=\left(1-\frac{\ln (\varphi)}{A_{d}}\right)^{\frac{-1}{n_{d}}}
\end{aligned}
$$

where $U$ is the actual water content $\left(\mathrm{kg} \cdot \mathrm{kg}^{-1}\right)$ for a fixed temperature, $U_{\max }$ the maximum water content, $\varphi$ the relative humidity of the air and $a$ and $d$ represent adsorption and desorption phenomenon respectively. The coefficients $\boldsymbol{A}_{\boldsymbol{a}}, \boldsymbol{A}_{\boldsymbol{d}}, \boldsymbol{n}_{\boldsymbol{a}}$ and $\boldsymbol{n}_{\boldsymbol{a}}$ are calculated using the least squares method based on the experimental results of sorption curves of Lelievre et al. [8].

Water content $\mathrm{U}\left(\mathrm{kg}_{\mathrm{kg}} \mathrm{kg}^{-1}\right)$ could be transformed into volumetric water content $\theta$ via relation (16): 


$$
\theta=U \times \frac{\rho_{0}}{\rho_{l}}
$$

Pedersen's approach for hysteresis is based on the weighted values of the moisture capacity or on the slope of adsorption and desorption curves described by:

$$
\begin{aligned}
& \xi_{a}=\frac{\partial U_{a}}{\partial \varphi} \\
& \xi_{d}=\frac{\partial U_{d}}{\partial \varphi}
\end{aligned}
$$

After a series of alternating processes of adsorption and desorption, intermediate scanning curves are modelled by [30]:

$$
\begin{aligned}
\xi_{\text {hyst }, a} & =\frac{\gamma_{a}\left(U-U_{a}\right)^{2} \xi_{d}+\left(U-U_{d}\right)^{2} \xi_{a}}{\left(U_{d}-U_{a}\right)^{2}} \\
\xi_{\text {hyst }, d} & =\frac{\left(U-U_{a}\right)^{2} \xi_{d}+\gamma_{d}\left(U-U_{d}\right)^{2} \xi_{a}}{\left(U_{d}-U_{a}\right)^{2}}
\end{aligned}
$$

$\gamma_{a}$ and $\gamma_{d}$ depend on the type of the material studied. For the case of hemp concrete, they can be fitted based on the experiments of the moisture buffering value of the hemp concrete done by Lelievre et al. according to the NordTest protocol [8] as shown in Fig.1.

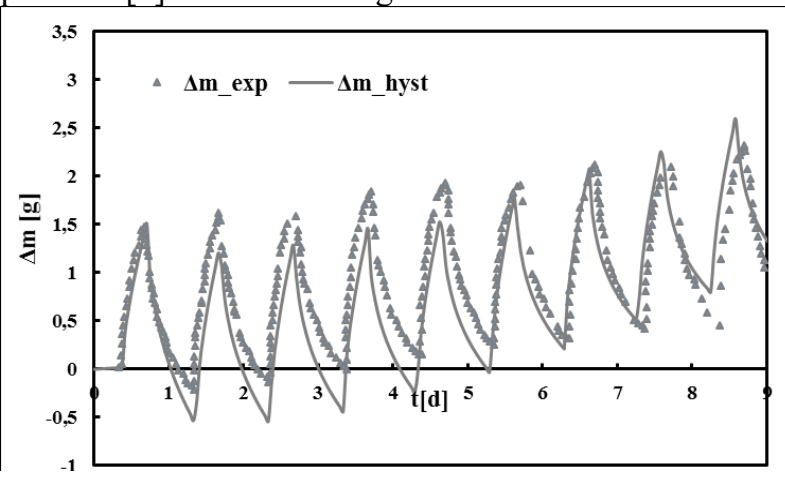

Fig. 1. Mass variations of hemp concrete specimen during the NordTest experience.

Fig.1 shows a convergence of the specimen mass during the repeating cycles (adsorption - desorption). $\gamma_{a}$ and $\gamma_{d}$ are set to 0.85 and 0.97 respectively in the numerical model including hysteresis.

\subsection{Sorption curves temperature dependency}

Temperature dependency of the sorption curves of hemp concrete is considered by allowing several sorption curves to describe the sorption characteristics at different temperature levels. So far, the study of the temperature effect on the sorption characteristics for bio-based materials is a new task. Researches have shown that the sorption capacity of materials depends on the temperature: increasing temperature entails that the isosteric moisture content can be reached in equilibrium with a higher relative humidity [12]. Three main reasons can explain this phenomenon [30]: firstly, the microstructure alteration due to the temperature (for example, the enlargements of pores can be attributed to a rise of temperature). Secondly, the modification of water thermophysical properties with temperature and finally, the thermodynamic evolution of sorption mechanism (the exothermic process of adsorption). In the case of hemp concrete, Oumeziane [9] proved the necessity of considering the temperature effect in modelling its hygrothermal behavior. Moreover, Rode and Clorius [31] worked on the coupling between temperature and hysteresis effects and proved that an increase of temperature results in a reduction of the hysteresis loop. Poyet and Charles [32] proposed a model describing the relation between sorption characteristics at different temperatures and based on the differential heat of sorption which can be written as follows:

$$
\begin{aligned}
& \varphi_{2}\left(T_{2}, \theta\right) \\
& =\varphi_{1}\left(T_{1}, \theta\right) \frac{P_{\text {sat }}\left(T_{1}\right)}{P_{\text {sat }}\left(T_{2}\right)} e^{q_{s t}(\theta) \frac{M_{1}}{R}\left(\frac{T_{2}-T_{1}}{T_{1} T_{2}}\right)}
\end{aligned}
$$

where $\mathrm{M}_{1}$ is water molar mass $\left(\mathrm{kg} \cdot \mathrm{mol}^{-1}\right), \mathrm{R}$ the ideal gas constant $\left(\mathrm{J} \cdot \mathrm{mol}^{-1} \cdot \mathrm{K}^{-1}\right)$, and $\mathrm{q}_{\mathrm{st}}$ the isosteric heat $\left(\mathrm{J} \cdot \mathrm{kg}^{-1}\right)$ calculated from two sorption isotherms at two different temperatures $\left(\mathrm{T}_{1}\right.$ and $\left.\mathrm{T}_{2}\right)$ as shown in Fig.2.

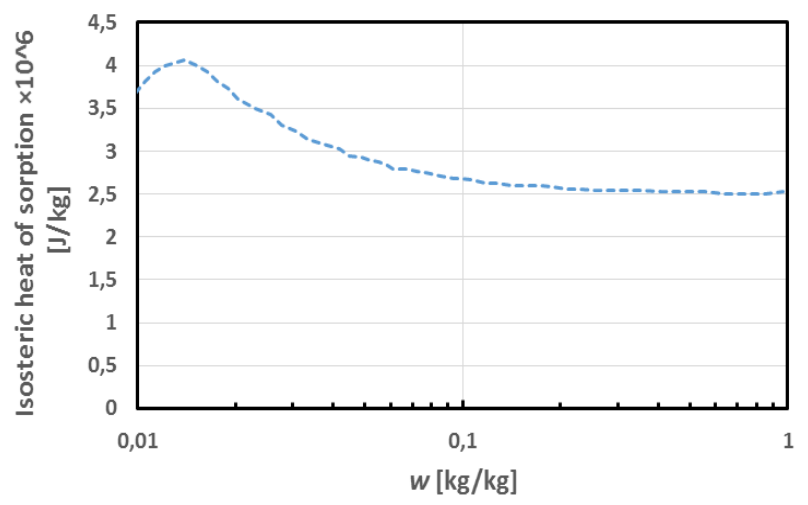

Fig. 2. Isosteric heat of sorption (Poyet and Charles Model).

\subsection{Simulation environment SPARK}

In order to solve the previous equation system, the Simulation Problem Analysis and Research Kernel (SPARK) tool is used [33]. Numerical solution is based on finite difference iterative method. SPARK allows solving efficiently differential equation systems. Each component is represented by an object that contains its appropriate mathematical model. Equations are defined in a generic matter called classes. Model is completed by linking objects together.

Using relation (21), main sorption curves are computed and implemented in SPARK respecting the form of equations (14) and (15), where $\boldsymbol{n}$ is a constant calibrated on the average sorption curve between main adsorption and desorption curves, $\mathrm{U}_{\max }\left(\right.$ Or $\left.\theta_{\max }\right)$ a 
linear function of the temperature, and $A_{a}=A_{d}=A$ with $A$ a linear function of the temperature as well. Figure 3 shows a $3 \mathrm{D}$ representation $(\varphi, \theta$, and $\mathrm{T})$ of the sorption curves.

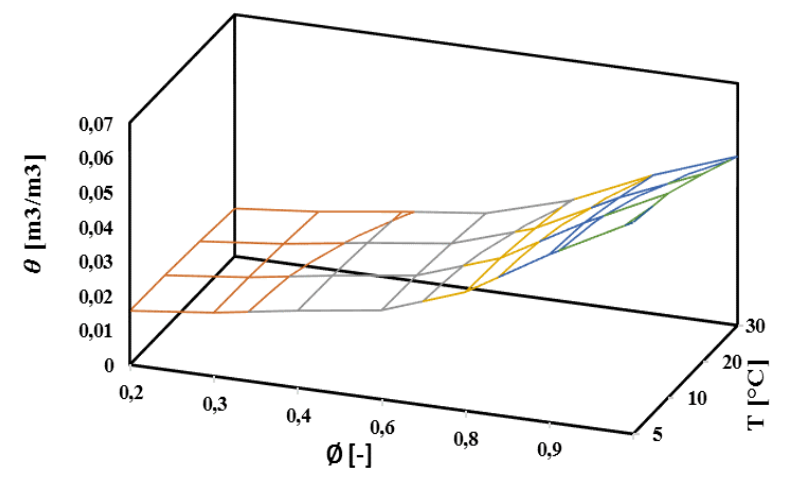

Fig. 3. 3D representation of sorption curves.

\section{Numerical validation}

Numerical models are investigated at the wall scale through a comparison between simulation results and experimental data provided by Lelievre et al [8]. The sample studied is a single layer wall composed of $36 \mathrm{~cm}$ of hemp concrete, subjected during 87 days to indoor and outdoor conditions for temperature and relative humidity as shown in Fig.4. Temperature and relative humidity through the wall are monitored at three different locations using specific sensors. Properties of hemp concrete are listed in Table 1.

Table 1. Hemp concrete properties.

\begin{tabular}{|c|c|}
\hline Properties & Hemp concrete \\
\hline $\begin{array}{c}\text { Thermal conductivity } \\
{\left[\mathrm{W} \cdot \mathrm{m}^{-1} \cdot \mathrm{K}^{-1}\right]}\end{array}$ & $\rho=450$ \\
\hline $\begin{array}{c}\text { Density } \\
{\left[\mathrm{Kg}^{-3} \mathrm{~m}^{-3}\right]}\end{array}$ & $\mathrm{C}_{\mathrm{p}}=1000$ \\
\hline $\begin{array}{c}\text { Thermal capacity } \\
{\left[\mathrm{J} \cdot \mathrm{kg}^{-1} \cdot \mathrm{K}^{-1}\right]}\end{array}$ & $\mu=5$ \\
\hline $\begin{array}{c}\text { Coefficient of } \\
\text { resistance to vapor }[-]\end{array}$ & \\
\hline
\end{tabular}

Four models are tested and compared, labelled respectively Mod_1, Mod_2, Mod_3 and Mod_4. Their characteristics are presented in Table 2.

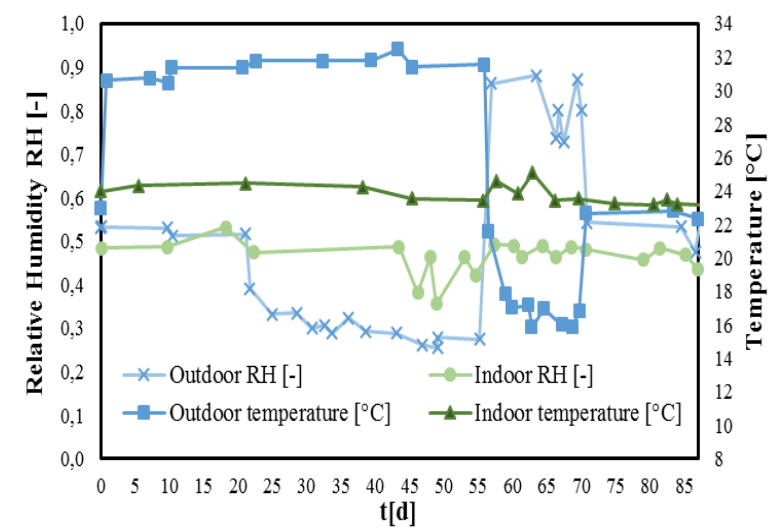

Fig. 4. Experimental test conditions.
Table 2. Numerical models characteristics.

\begin{tabular}{|c|l|}
\hline Models & \multicolumn{2}{|c|}{ Description } \\
\hline & $-\begin{array}{l}\text { Standard model for heat and } \\
\text { moisture transfer with average } \\
\text { sorption curve } \\
\text { Initial conditions at } 23^{\circ} \mathrm{C} \text { and } 50 \% \\
\text { relative humidity }\end{array}$ \\
\hline Mod_2 & - $\begin{array}{l}\text { Model for heat and moisture transfer } \\
\text { including hysteresis } \\
\text { Initial conditions at } 23^{\circ} \mathrm{C} \text { and } 50 \% \\
\text { relative humidity from adsorption } \\
\text { curve }\end{array}$ \\
\hline Mod_3 & $-\begin{array}{l}\text { Model for heat and moisture transfer } \\
\text { including temperature dependency } \\
\text { Initial conditions at } 23^{\circ} \mathrm{C} \text { and } 50 \% \\
\text { relative humidity }\end{array}$ \\
\hline Mod_4 & $\begin{array}{l}\text { Global model for heat and moisture } \\
\text { transfer including both hysteresis } \\
\text { and temperature dependency } \\
\text { Initial conditions at } 23^{\circ} \mathrm{C} \text { and } 50 \% \\
\text { relative humidity from desorption } \\
\text { curve }\end{array}$ \\
\hline
\end{tabular}

The results for relative humidity and temperatures are plotted at the three different locations monitored in the sample: $x=5 \mathrm{~cm}, x=18 \mathrm{~cm}$ and $x=29 \mathrm{~cm}$.

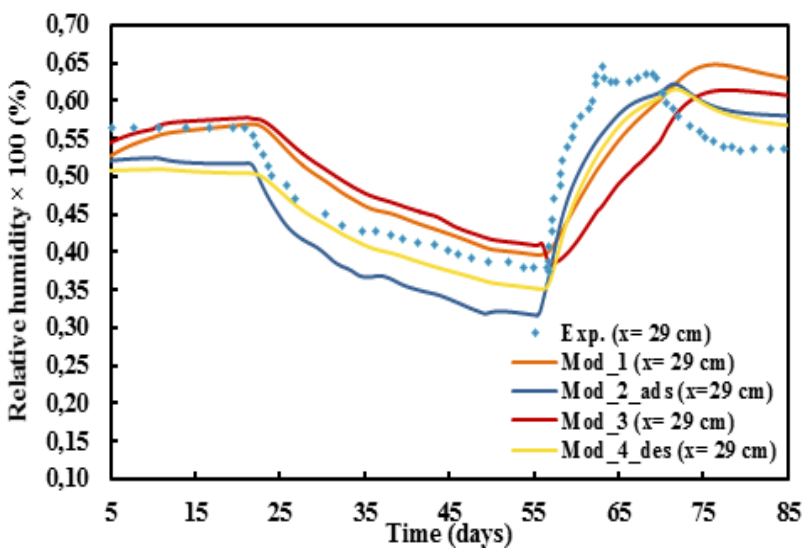

Fig. 5. Comparison between relative humidity profiles at $\mathrm{x}=$ $29 \mathrm{~cm}$.

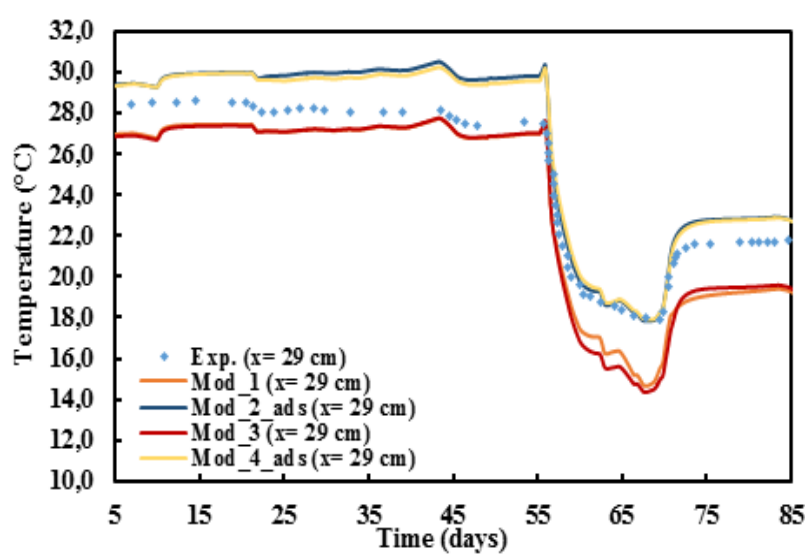

Fig. 6. Comparison between temperature profiles at $x=29 \mathrm{~cm}$.

At $x=29 \mathrm{~cm}$, temperature profiles obtained (Fig. 5) are acceptable for the four models up to the $57^{\text {th }}$ day with 
an underestimation (between $0.5^{\circ} \mathrm{C}$ and $2{ }^{\circ} \mathrm{C}$ ) for the Mod_1 and Mod_3 and an overestimation (from 1.5 to 2 $\left.{ }^{\circ} \mathrm{C}\right)$ of the temperature for Mod_2 and Mod_4. Beyond that, the temperature is advantageous for Mod_2 and Mod_4 and deteriorated for Mod_1 and Mod_3 with differences reaching $4^{\circ}$ C. Fig. 6 shows that when the temperature is overestimated after the first 57 days, the relative humidity is overestimated and vice versa, with remarkable advantages for Mod_4 whose deviations from the experimental do not exceed $\overline{5 \%}$. From 57 days, Mod 2 and Mod 4 represent well the dynamic appearance of the variations while Mod_1 and Mod_3 show reduced slope and delayed relative humidity peaks.

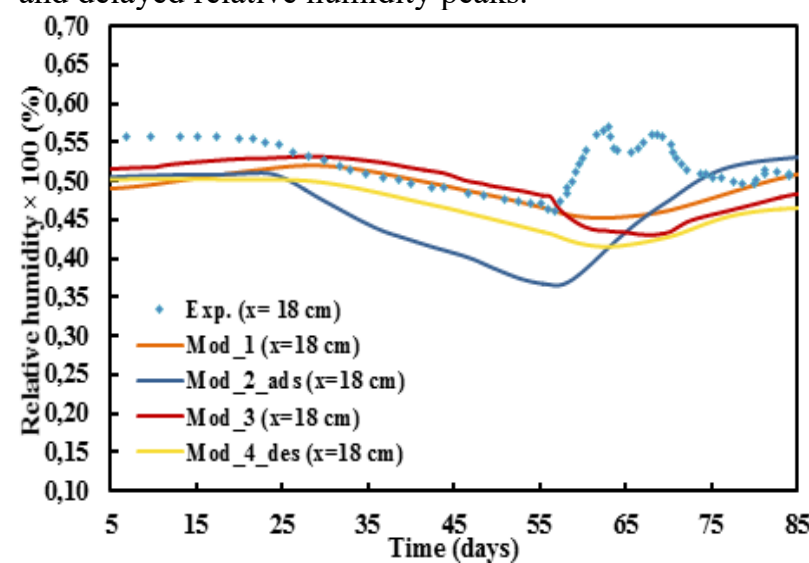

Fig. 7. Comparison between relative humidity profiles at $\mathrm{x}=$ $18 \mathrm{~cm}$.

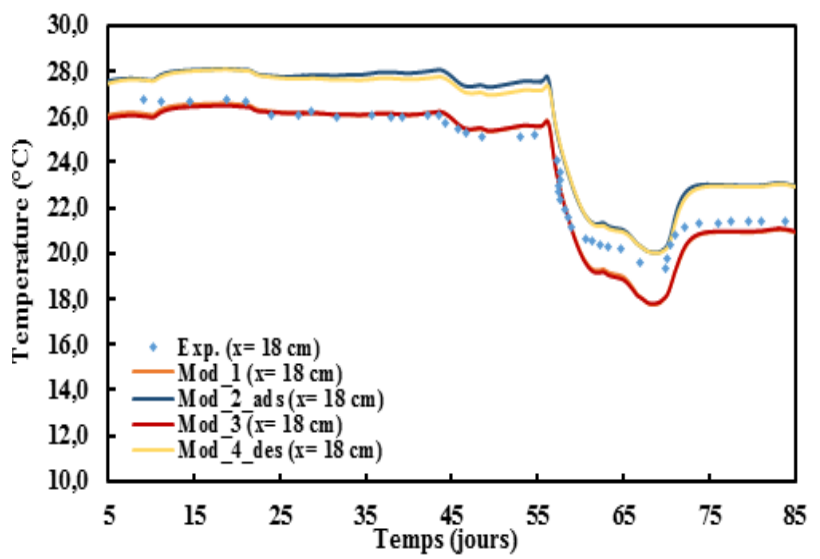

Fig. 8. Comparison between temperature profiles at $x=18 \mathrm{~cm}$.

In the middle of the wall (Fig. 7), the prediction of the dynamic behaviour of relative humidity is acceptable until day 57 especially for Mod_1 and Mod_4. Beyond this, the profiles do not fit well with the experimental data for the four models. For the temperature profiles (Fig. 8), the curves obtained stick well with the experimental values for Mod_1 and Mod 3 during the 57 days, while they are overestimated by $2^{\circ} \mathrm{C}$ for Mod_2 and Mod_4. In the last twenty days, the results remain advantageous for Mod_1 and Mod_3 (maximum deviations of $1.5^{\circ} \mathrm{C}$ ).

Figure 10 shows that the models are reliable for the prediction of temperature changes on the indoor side of the wall since the deviations with the experimental measurements do not exceed $1{ }^{\circ} \mathrm{C}$ in $\mathrm{x}=5 \mathrm{~cm}$. Fig. 9 gives the advantage to Mod_1 and Mod_3, and especially Mod_1, with maximum differences of about $2 \%$ with the experimental when Mod_2 succeeds in predicting the dynamics of variations and Mod_4 presents acceptable results but a little more spread at the end ( $7 \%$ difference with the experimental).

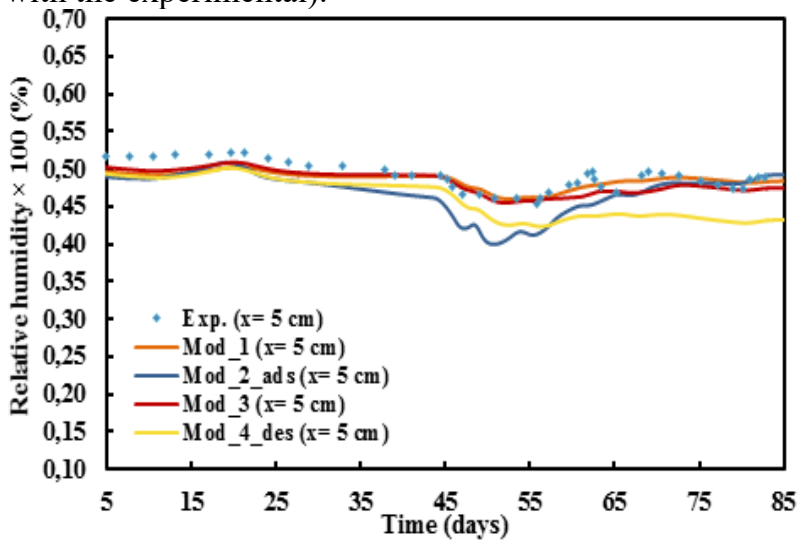

Fig. 9. Comparison between relative humidity profiles at $x=5$ $\mathrm{cm}$.

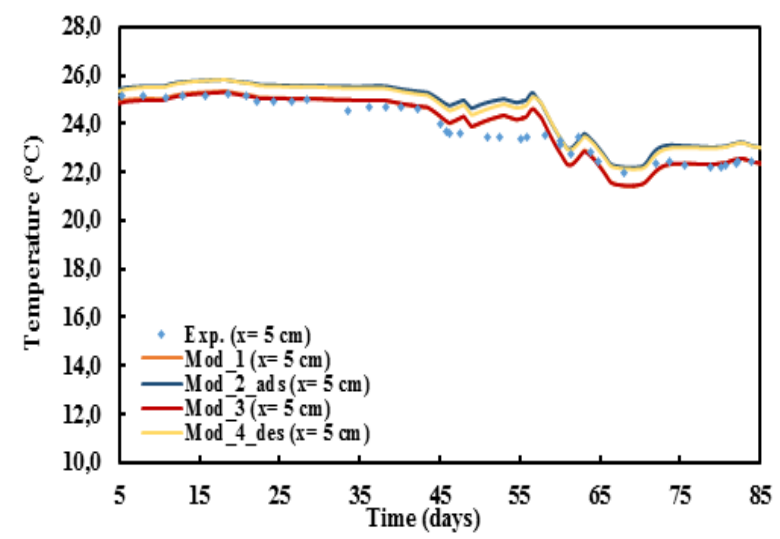

Fig. 10. Comparison between temperature profiles at $x=5 \mathrm{~cm}$.

Thus, considering hysteresis improves the prediction of dynamic variations in temperature and relative humidity when the wall is subjected to these variable conditions. In addition, additional improvements are made by coupling hysteresis and temperature dependence following the results obtained by Mod 4 .

\section{Conclusion}

This paper deals with hygrothermal behaviour study of hemp concrete via four numerical models. The hysteresis and temperature dependency phenomena are studied separately and then coupled together. Results are compared with the standard model for heat and moisture transfer. Comparison shows that predicting relative humidity profiles from the outer wall highly depends on the chosen model and presents improvements when hysteresis is considered. In parallel, temperature profiles are also improved with hysteresis at this wall side. Concerning the inner side, the four models show acceptable results for temperature and relative humidity. Thus, studying phenomena occurring within the wall requires particular attention to the selected model whereas results about investigations on indoor ambiant conditions could be reliable based on one of these four models.

This work is supported by the Champagne Ardennes region and the FEDER (Fonds Européen de Développement Régional). 


\section{References}

[1] RT, "La RT2012: un saut énergétique pour les bâtiments neufs - Ministère de l'Environnement, de l'Energie et de la Mer," (2012)

[2]. :: "United Nations Environment Programme (UNEP) - SBCI :.:" [Online]. Available: http://www.unep.org/sbci/. [Accessed: 15-Dec2016].

[3] F. D'Alessandro, F. Asdrubali, and G. Baldinelli, "Multi-parametric characterization of a sustainable lightweight concrete containing polymers derived from electric wires," Constr. Build. Mater., vol. 68, pp. 277-284, (2014)

[4] F. Asdrubali, F. D’Alessandro, and S. Schiavoni, "A review of unconventional sustainable building insulation materials," Sustain. Mater. Technol., vol. 4, pp. 1-17, (2015)

[5] F. Collet, "Caractérisation hydrique et thermique de matériaux de génie civil à faibles impacts enivoronnementaux," Instittut National des Sciences Appliquées de Rennes, (2004)

[6] V. Cerezo, "Propriétés mécaniques, thermiques et acoustiques d'un matériau à base de particules végétales : approche expérimentale et modélisation théorique," Institut National des Sciences Appliquées de Lyon, Ecole Nationale des Travaux Publics de l'Etat, (2005)

[7] S. Elfordy, F. Lucas, F. Tancret, Y. Scudeller, and L. Goudet, "Mechanical and thermal properties of lime and hemp concrete ('hempcrete') manufactured by a projection process," Constr. Build. Mater., vol. 22, no. 10 , pp. 2116-2123, (2008)

[8] D. Lelievre, T. Colinart, and P. Glouannec, "Hygrothermal behavior of bio-based building materials including hysteresis effects: Experimental and numerical analyses," Energy Build., vol. 84, pp. 617-627, Dec. (2014)

[9] Y. Ait Ouméziane, "Evaluation des performances hygrothermiques d'une paroi par simulation numérique: application aux parois en béton de chanvre," INSA de Rennes, (2013)

[10] G. Promis, O. Douzane, A. D. Tran Le, and T. Langlet, "Moisture hysteresis influence on mass transfer through bio-based building materials in dynamic state," Energy Build., vol. 166, pp. 450459, May (2018)

[11]T. Colinart, P. Glouannec, M. Bendouma, and P. Chauvelon, "Temperature dependence of sorption isotherm of hygroscopic building materials. Part 2: Influence on hygrothermal behavior of hemp concrete," Energy Build., vol. 152, pp. 42-51, Oct. (2017)

[12]A. D. T. Le, D. Samri, M. Rahim, O. Douzane, G. Promis, and T. Langlet, "Effect of Temperaturedependent Sorption Characteristics on The Hygrothermal Behavior of Hemp Concrete," Energy Procedia, vol. 78, pp. 1449-1454, (2015)
[13] A. D. Tran Le, "Etude des transferts hygrothermiques dans le béton de chanvre et leur application au bâtiment," Université de Reims-ChampagneArdenne, (2010)

[14] M. Künzel Hartwig, Simultaneous Heat and Moisture Transport in Building Components: One and two dimentional calculation using simple parameters. Suttgart, (1995)

[15] N. Mendes, I. Ridley, P. C. Philippi, and K. Budag, "Umidus: a PC Program For The Prediction Of Heat And Mass Transfer In Porous Building Elements," Kyoto, Japan: Building Simulation'99 Conference, 1999: 1 - 7.

[16] J. R. Philip and D. A. De Vries, "Moisture movement in porous materials under temperature gradients," Trans. Am. Geophys. Union, vol. 38, no. 2, p. 222, (1957)

[17] Kerestecioglu A. and Gu L., "Incorporation of the effective penetration depth theory into TRNSYS," Draft Report, Florida Solar Energy Center, Cape Canaveral, FL., (1989)

[18] W.C Burch D.M and Thomas, "An analysis of moisture accumulation in a wood frame wall subjected to winter climate," National Institute of Standards and Technololgy., (1991)

[19]A. Ozaki, T. Watanabe, T. Hayashi, and Y. Ryu, "Systematic analysis on combined heat and water transfer through porous materials based on thermodynamic energy," Energy Build., vol. 33, no. 4, pp. 341-350, Apr. (2001)

[20]P. Crausse, J. . Laurent, and B. Perrin, "Influence des phénomènes d'hystérésis sur les propriétés hydriques de matériaux poreux: Comparaison de deux modèles de simulation du comportement thermohydrique de parois de bâtiment," Rev. Générale Therm., vol. 35, no. 410, pp. 95-106, (1996)

[21]F. Collet, M. Bart, L. Serres, and J. Miriel, "Porous structure and water vapour sorption of hemp-based materials," Constr. Build. Mater., vol. 22, no. 6, pp. 1271-1280, (2008)

[22]Y. Mualem, "A conceptual model of hysteresis," Water Resour. Res., vol. 10, no. 3, pp. 514-520, Jun. (1974)

[23]J. B. Kool and J. C. Parker, "Development and evaluation of closed-form expressions for hysteretic soil hydraulic properties," Water Resour. Res., vol. 23, no. 1, pp. 105-114, (1987)

[24]C. R. Pedersen, "Transient calculation on moisture migration using a simplified description of hysteresis in the sorption isotherms," Proc. 2nd Symp. Build. Phys. Nord. Ctries., no. Technical University of Norway, Trondheim, Norway., (1990)

[25]H.-J. Steeman, "Modelling local hygrothermal interaction between airflow and porous materials for building applications", dissertation, Ghent University, (2009).

[26] M. Van Belleghem, H.-J. Steeman, M. Steeman, A. Janssens, and M. De Paepe, "Sensitivity analysis of 
CFD coupled non-isothermal heat and moisture modelling," Build. Environ., vol. 45, no. 11, pp. 2485-2496, (2010)

[27]D. Samri, "Analyse physique et caractérisation hygrothermique des matériaux de construction", $\mathrm{PhD}$ INSA de Lyon, (2008)

[28] D. Lelievre, "Simulation numérique des transferts de chaleur et d'humidité dans une paroi multicouche de bâtiment en matériaux biosourcés", Université Bretagne-Sud, (2015)

[29] K. K. Hansen, "Sorption Isotherms. A Catalogue," Copenhagen, (1986)

[30] Y. Aït Oumeziane, S. Moissette, M. Bart, and C. Lanos, "Influence of temperature on sorption process in hemp concrete," Constr. Build. Mater., vol. 106, pp. 600-607, (2016)

[31]C. Rode and C. O. Clorius, "Modeling of Moisture Transport in Wood with Hysteresis and TemperatureDependent Sorption Characteristics," in ASHRAE, (2004)

[32] S. Poyet and S. Charles, "Temperature dependence of the sorption isotherms of cement-based materials: Heat of sorption and Clausius-Clapeyron formula," Cem. Concr. Res., vol. 39, no. 11, pp. 1060-1067, (2009)

[33]E. F. Sowell and P. Haves, "Efficient solution strategies for building energy system simulation," Build. Phys., vol. 33, pp. 309-317,( 2001) 